\title{
Corpo estranho gástrico em um coelho (Oryctolagus cuniculus)
}

\author{
Gastric foreign body in a rabbit (Oryctolagus cuniculus) \\ Márcio Poletto Ferreira ${ }^{1}$, Marcelo Meller Alievi ${ }^{2}$, Carlos Afonso de Castro Beck ${ }^{2}$, \\ Antônio de Pádua Ferreira da Silva Filho², Eduardo Bastos Santos J únior ${ }^{3}$, \\ Wanessa Beheregaray ${ }^{4}$, Rafael Stédile ${ }^{1} \&$ Paula Cristina Sieczkowski Gonzalez ${ }^{4}$
}

\begin{abstract}
RESUMO
Os coelhos domésticos, devido ao temperamento dócil e facilidade de criação, tornaram-se animais de companhia adotados com frequiência atualmente, o que leva à um aumento no atendimento à estes animais. Não é incomum que coelhos apresentem bolas de pêlo em seu estômago, mas outros objetos podem provocar obstruções graves. O presente trabalho relata o caso de um coelho doméstico, fêmea, três anos, que foi trazido ao Hospital de Clínicas Veterinárias da Universidade Federal do Rio Grande do Sul (HCV/UFRGS) por ter ingerido uma agulha de costura. O animal apresentava-se anoréxico e prostrado. No exame radiográfico foi verificado que a agulha encontrava-se no lúmen gástrico. O paciente foi encaminhado para o setor de cirurgia do HCV/UFRGS onde foi pré-medicado com Diazepan $(2 \mathrm{mg} / \mathrm{kg})$ e meperidina (10 mg/kg), a indução anestésica foi feita com propofol $(6 \mathrm{mg} / \mathrm{kg})$ e foi mantido em plano anestésico com isofluorano. O animal foi submetido a gastrotomia e posterior remoção do corpo estranho metálico e tricobezoares. Após dez dias do procedimento cirúrgico, o animal encontrava-se clinicamente bem e alimentava-se adequadamente.
\end{abstract}

Descritores: corpo estranho, estômago, coelho, gastrotomia, tricobezoares.

\section{ABSTRACT}

The domestic rabbit (Oryctolagus cuniculus) became a common pet nowadays, therefore the number of animals treated increases day after day. Is not rare to find hairballs inside the stomach of rabbits, but other objects may cause serious obstruction. The present works tells the case of a 3-year-old, female, domestic rabbit that was referred to the Veterinary Teaching Hospital of Federal University of Rio Grande do Sul due to sewing needle ingestion. Radiography examination showed the sewing needle in the gastric lumen. Treatment consisted of gastrotomy and removing the needle. By 10 days after surgery, the rabbit was clinically well and eating normally.

Key words: foreign body, stomach, rabbit, gastrotomy. Medicina Veterinária - UFSM. ${ }^{4}$ Graduação da FaVet/UFRGS. CORRESPONDÊNCIA: M.P. Ferreira [marciopf@ terra.com.br]. 


\section{INTRODUÇÃO}

Os coelhos domésticos (Oryctolagus cuniculus), devido à facilidade de criação e ao temperamento dócil, estão sendo cada vez mais criados como animais de companhia e, com isso, têm apresentado afecções antes comuns apenas aos cães e gatos, como por exemplo, a presença de corpo estranho gástrico. Isso resulta em uma crescente solicitação de serviços veterinários para esta espécie, tornando-se necessária a capacitação profissional para atendê-la $[2,6]$.

Os animais desta espécie não têm a capacidade de vomitar, desta maneira, materiais estranhos como bolas de pêlo não podem ser expelidos pela via oral, o que normalmente ocorreria em outras espécies, como felinos e caninos, dessa forma estes corpos estranhos têm a capacidade de provocar obstruções graves [2,3]. É comum nesta espécie a formação de tricobezoares, que são acúmulos de pêlo na forma de bolas presentes no lúmen estomacal podendo isto ocorrer também em felinos [1], ratos [8], bovinos [9], eqüinos [7] e humanos [10].

Os sinais clínicos mais comuns em coelhos com corpo estranho gástrico são: anorexia, letargia, perda de peso, oligodipsia, diarréia, desidratação, prostração, abdômen tenso, hipotermia, timpanismo [5,6] e decréscimo na defecação [4]. O diagnóstico é feito baseando-se na anamnese, nos achados do exame clínico, como a palpação de uma massa abdominal na área anatômica do estômago, e no exame radiográfico [6], embora não se consiga diferenciar, na radiografia, um tricobezoar do conteúdo gástrico normal [4].

O trabalho tem por objetivo relatar o caso de um coelho doméstico, fêmea, três anos, atendido no Hospital de Clínicas Veterinárias de Universidade Federal do Rio Grande do Sul (HCV-UFRGS), que foi submetido a gastrotomia para retirada de um corpo estranho.

\section{RELATO DE CASO}

Um coelho doméstico, fêmea, foi trazida ao Hospital de Clínicas Veterinárias (HCV) com histórico de ter ingerido uma agulha de costura no dia anterior. $\mathrm{Na}$ anamnese, foi relatado que o animal apresentavase anoréxico, e prostrado, sendo que o proprietário informou que o alimentava com comida caseira. Ao exame clínico, a temperatura retal, freqüências cardíaca e respiratória, pulso, hidratação e coloração das mucosas encontravam-se dentro dos valores normais para a espécie, sendo então, solicitado exame radiográfico abdominal, no qual foi constatada a presença de uma agulha metálica no lúmen estomacal, sendo indicada a sua remoção cirúrgica (Figura 1).

$\mathrm{O}$ animal foi encaminhado para o setor de cirurgia do $\mathrm{HCV}$, onde recebeu como medicação préanestésica diazepam, na dose de $2 \mathrm{mg} / \mathrm{kg}$, e meperidina, na dose de $10 \mathrm{mg} / \mathrm{kg}$, ambos intramusculares. Após 15 minutos, a indução anestésica foi realizada com propofol, na dose de $6 \mathrm{mg} / \mathrm{kg}$, pela via intravenosa, e a manutenção anestésica foi efetuada com isoflurano em circuito anestésico semi-fechado.

Após a anti-sepsia com álcool iodado, a cavidade abdominal foi acessada através de celiotomia mediana pré-umbilical. Assim que se localizou o estômago, este foi exteriorizado utilizando-se reparos, e submetido à gastrotomia em região hipovascular. Durante a inspeção do estômago, foram retirados a agulha metálica (Figura 2) e tricobezoares pequenos $(2-3 \mathrm{~cm})$. A gastrorrafia foi realizada em duas camadas, inicialmente com sutura contínua simples e após com sutura de Cushing, utilizando mononáilon 4-0. A celiorrafia e a reaproximação do tecido subcutâneo foi realizada com sutura contínua simples e fio de ácido poliglicólico 3-0, e a sutura de pele foi realizada com pontos isolados simples e fio mononáilon 4-0. No pós-operatório, o animal foi medicado com cetoprofeno (2 $\mathrm{mg} / \mathrm{kg}$ SID/IM), durante 4 dias, e com enrofloxacina (15 mg/kg SID/IM), durante 10 dias. Também foi realizado exame radiográfico do abdômen onde foi verifica a ausência de corpos estranhos radiopacos. Foi recomendado ao proprietário que alimentasse o animal com ração comercial juntamente com verduras e pasto.

Passados 10 dias da realização do procedimento, o animal apresentava-se alerta e alimentando-se normalmente, recebendo, dessa forma, alta clínica após a remoção da sutura de pele.

\section{DISCUSSÃO}

Em alguns casos encontrados na literatura [4] foi utilizada alimentação forçada nos primeiros 10 dias de pós-operatório, composta por $30 \mathrm{ml}$ de um concentrado altamente calórico com cultura de Lactobacillus ou iogurte, junto com dextrose a 50\%. Neste caso, não foi necessário alimentação forçada, pois o animal já estava alimentando-se adequadamente no primeiro dia após a cirurgia.

Acredita-se que a agulha encontrada no lúmen gástrico do animal de nosso relato tenha provocado a sintomatologia clínica, sendo a presença de tricobezoares apenas um achado trans-operatório, visto que 


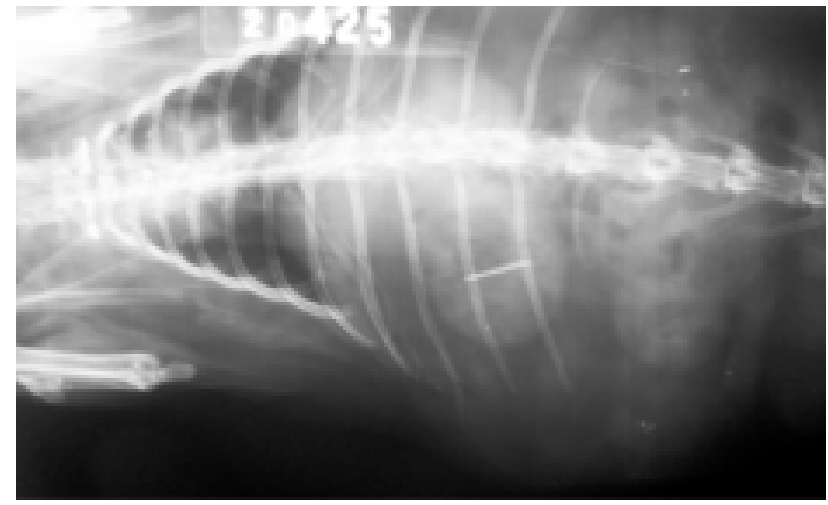

Figura 1. Exame radiográfico ventrodorsal do lúmen estomacal de coelho doméstico evidenciando a presença de corpo estranho radiopaco.

nesta espécie é comum a ingestão de uma pequena quantidade de pêlo, sem que isto cause obstrução no trato digestivo. É difícil precisar o que levou o animal a ingerir a agulha, mas o fato do animal receber exclusivamente dieta caseira formada por sobras da comida de humanos pode ter provocado uma deficiência nutricional levando o animal a ter um apetite não convencional.

A palpação abdominal não foi realizada durante o exame clínico devido ao histórico de ingestão de objeto perfurante, pois esta manobra poderia provocar a perfuração da parede estomacal pelo corpo estranho. Os tricobezoares encontrados durante a cirur-

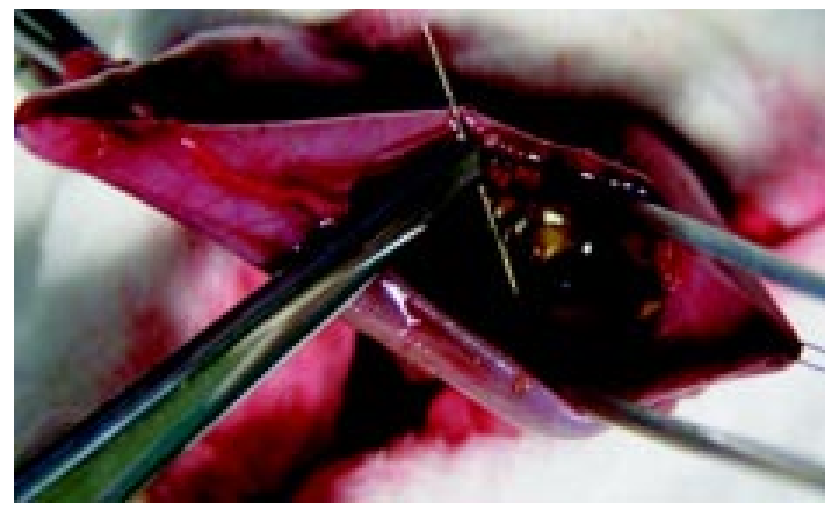

Figura 2. Gastrotomia em coelho doméstico evidenciando o momento da retida do corpo estranho.

gia não foram observados durante o exame clínico, tampouco no exame radiográfico, fato este que corrobora com a literatura que cita ser improvável a diferenciação entre um tricobezoar e conteúdo gástrico normal [4].

É preferível a utilização de fio absorvível sintético nas suturas abdominais de coelhos para minimizar aderências pós-cirúrgicas, visto que a ocorrência dessa complicação pós-operatória é muito comum nesta espécie, principalmente quando se utiliza fios absorvíveis não sintéticos como o catgut [2]. Com isso, foi escolhido o fio absorvível sintético de ácido poliglicólico para a sutura da parede abdominal.

\section{REFERÊNCIAS}

1 Barrs V.R., Beatty J.A., Tisdall P.L.C., Hunt G.B., Gunew M., Nicoll R.G. \& Malik R. 1999. Intestinal obstruction by trichobezoars in five cats. Journal of Feline and Medicine Surgery. 1: 199-207.

2 Brown S.A. 1997. Clinical Techniques in rabbits. Seminars in Avian and Pet Medicine. 6: 86-95.

3 Crossley D.A. \& Meredith A. 2002. Rabbits. In: Meredith A. \& Redrobe S. (Eds). BSAVA Manual of Exotic Pets. 4th edn. Gloucester: BSAVA, pp.76-92.

4 Gillett N.A., Brooks D.L. \& Tillman P.C. 1983. Medical and surgical management of gastric obstruction from a hairball in the rabbit. Journal of the American Veterinary Medical Association. 183: 1176-1178.

5 Harkness J.E. \& Wagner J.E. 1990. Biologia clínica de coelhos e roedores. 3.ed. São Paulo: Roca, pp.209-210.

6 Hoyt R.F. 2001. Cirugía abdominal de los conejos. In: Bojrab M.J. (Ed). Tecnicas actuales em cirugia de pequeños animales. 4.ed. Buenos Aires: Inter-Medica, pp.720-732.

7 Kellam L.L., Johnson P.J., Kramer J. \& Keegan K.G. 2000. Gastric impaction and obstruction of the small intestine associated with persimmon phytobezoar in a horse. Journal of the American Veterinary Medical Association. 216: $1279-1281$.

8 Krugner-Higby L., Wolden-Hanson T., Gendron A. \& Atkinson R.L. 1996. High prevalence of gastric trichobezoar (hair balls) in Wistar-Kyoto rats fed a semi-purified diet. Laboratory Animal Science. 46: 635-639.

9 Martins A.M.C.R.P.F., Leme M.C.M., Portugal M.A.S.C., Baldassi L. \& Margatho L.F.F. 2004. Presença de corpos estranhos no aparelho digestório dos bovinos. Arquivos do Instituto Biológico. 71: 83-87.

10 Spadella C.T., Saad-Hossne R. \& Saad L.H.C. 1998. Tricobezoar gástrico: relato de caso e revisão da literatura. Acta Cirúrgica Brasileira. 13: 110-115.

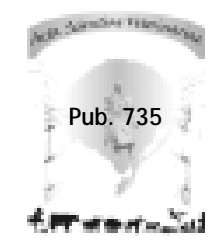

